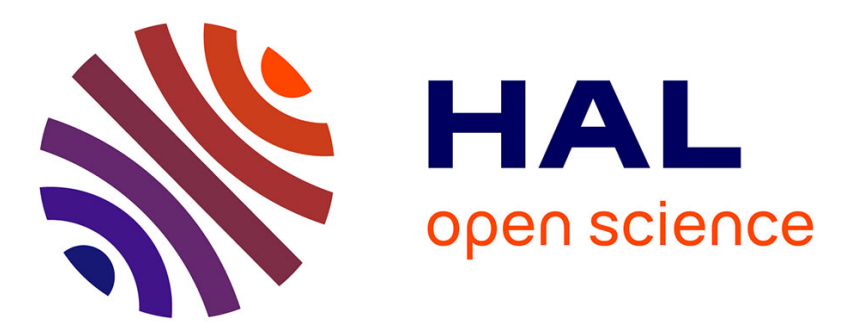

\title{
Enhanced dendrite fragmentation through the peritectic reaction in TiAl-based alloys
}

\author{
N.T. T Reilly, B. Rouat, G. Martin, D. Daloz, Julien Zollinger
}

\section{To cite this version:}

N.T. T Reilly, B. Rouat, G. Martin, D. Daloz, Julien Zollinger. Enhanced dendrite fragmentation through the peritectic reaction in TiAl-based alloys. Intermetallics, 2017, 86, pp.126-133. 10.1016/j.intermet.2017.03.022 . hal-02353584

\section{HAL Id: hal-02353584 \\ https://hal.univ-lorraine.fr/hal-02353584}

Submitted on 7 Nov 2019

HAL is a multi-disciplinary open access archive for the deposit and dissemination of scientific research documents, whether they are published or not. The documents may come from teaching and research institutions in France or abroad, or from public or private research centers.
L'archive ouverte pluridisciplinaire HAL, est destinée au dépôt et à la diffusion de documents scientifiques de niveau recherche, publiés ou non, émanant des établissements d'enseignement et de recherche français ou étrangers, des laboratoires publics ou privés. 


\title{
Enhanced dendrite fragmentation through the peritectic reaction in TiAl-based alloys
}

\author{
N.T. Reilly ${ }^{\mathrm{a}, \mathrm{b}}$, B. Rouat ${ }^{\mathrm{a}, \mathrm{c}}$, G. Martin ${ }^{\mathrm{b}}$, D. Daloz ${ }^{\mathrm{a}, \mathrm{c}}$, J. Zollinger $\mathrm{a}^{\mathrm{a}, \mathrm{c}, *}$ \\ ${ }^{a}$ Université de Lorraine, Institut Jean Lamour, Department of Metallurgy \& Materials Science and Engineering, \\ Parc de Saurupt, F-54011 Nancy, France. \\ ${ }^{b}$ SAFRAN Aircraft Engines, F-92702 Colombes Cedex, France \\ ${ }^{c}$ Laboratory of Excellence on Design of Alloy Metals for low-mAss Structures ('LabEx DAMAS'), France
}

\begin{abstract}
Grain size evolution for $\gamma$-TiAl based alloys with aluminum content ranging from 43 to 52 at. $\%$ were cast at constant superheat and characterized. Experiments show that the sooner the peritectic phase transition occurs, the finer are the equiaxed grains. An accurate estimate of the number of surviving dendrite fragments and fragmentation rate is performed, which can be used to predict the position of the columnar-to-equiaxed transition in the cast ingots. For alloys solidifying with the $\beta$ pro-peritectic primary phase, the fragmentation rate significantly increases when the onset of the peritectic reaction is earlier. A mechanism based on the peritectic reaction is proposed for the observed grain refinement and is discussed on the basis of the fluid flow, mushy zone permeability and the influence of the peritectic reaction.
\end{abstract}

Keywords: Solidification, Peritectic reaction, TiAl alloys, Dendrite fragmentation

\section{Introduction}

Over the years, various hypotheses have been formulated for the origin of equiaxed grains in the center of a casting in the absence of grain refiner particles. 90 years ago, Rosenhain suggested that equiaxed nuclei could originate as crystals transported downward by gravity from the top surface of the ingot or as crystals formed in the stream of liquid metal during pouring [1]. Other hypotheses for equiaxed grain sources included transport of the first nuclei to form on the mold walls or near the top of an ingot, Chalmers' "big bang" nucleation theory [2], or dendrite fragmentation. Over 60 years ago, Melia and Moffitt proposed that secondary arm detachment could be a source of grains for secondary nucleation [3], and this currently appears to be the main source of equiaxed grains in non-grain-refined cast alloys. Jackson et al. proposed a mechanism for local remelting of secondary arms at their bases provoked by fluctuations in the growth rate [4]. A uniform temperature increase can also provoke dendrite fragmentation [5]. The solidliquid interface curvature also contributes to fragmentation: the secondary dendrite arms have a larger curvature at the junction with the primary arms, decreasing the local melting point by the product of the Gibbs-Thomson constant with the curvature, $\Gamma \cdot K$. Most understanding of fragmentation stems from experiments on analog organic alloys, but recent in-situ studies involve $\mathrm{Al}-\mathrm{Cu}$, In-Ga or Sn-Bi alloys $[6,7,8,9,10,11]$. The fragmentation rate $\Phi$ varies widely in different studies, from $4 \cdot 10^{4}$ to $2.5 \cdot 10^{7} \mathrm{frag} \cdot \mathrm{m}^{-2} \mathrm{~s}^{-1}[12,13,14,15]$.

While it seems that detachment of secondary arms is more governed by dissolution/remelting than by mechanical fracture [16], natural or forced convection is a source of fragments $[4,13]$, as it can bring warm, solute-poor liquid from the bulk into the interdendritic region, driving local remelting [4, 14]. Paradies et al. provide a detailed literature review on the effects of stirring and convection [14].

Despite the considerable number of peritectic alloys, which include alloys of technological importance (steels, bronze, titanium aluminides), the role of the peritectic phase transition on fragmentation has not been thoroughly investigated. Only indirect and qualitative results can be found on the formation of the equiaxed zone in steels [17, 18]

${ }^{*}$ Corresponding author 
and stainless steels [19]. The peritectic phase transition comprises (i) the peritectic reaction, or the nucleation and growth of the peritectic phase at the liquid/pro-peritectic phase interface, and (ii) the peritectic transformation, the growth of the peritectic phase into both the liquid and the pro-peritectic phase [20]. Although seemingly straightforward, this phase transition can lead to a large variety of solidification microstructures, including coupled growth [21] and island banding [22, 23].

Evidence of the peritectic phase transition impacting fragmentation has only been observed by Yasuda et al. using $\mathrm{X}$-ray synchrotron radiation in steels [24]. The authors point out that the fragmentation induced by the peritectic phase transition is possible because of the high $\delta / \gamma$ surface tension $\sigma$, i.e. $\sigma_{\delta / \gamma}>2\left(\sigma_{\ell / \gamma}, \sigma_{\ell / \delta}\right)$ meaning the surface tension between the solid phases is twice as large as the solid / liquid surface tensions, which leads to a triple point behaving similarly to grain boundary melting. In $\gamma$ - TiAl alloys, the peritectic phase transition seems to affect the grain size of cast-samples [25], but in this case the interface energy between the pro-peritectic $\beta$ - Ti and the peritectic phase $\alpha$ - Ti is expected to be relatively low thanks to the Burgers orientation relationships between the two phases [26].

Practically, without grain refiners, fragmentation is the source of equiaxed grains, which, under favorable local growth conditions, can block columnar growth and cause a columnar-to-equiaxed transition (CET), which influences material properties. Spittle [27] provides an in-depth review of the phenomenon, and Hunt's analytical model establishes a mechanical blocking criterion for CET [28]. Little work has been done on the CET in peritectic systems. A larger equiaxed zone correlated with the peritectic transition was observed only in the case of a high superheat (90 ${ }^{\circ} \mathrm{C}$ ) in Fe-C alloys, with no such correlation for a superheat of $50{ }^{\circ} \mathrm{C}$ [18]. High superheats are supposed to encourage dendrite arm remelting, which could mean the larger equiaxed zone results from the presence of extra nuclei [29].

The present work is a study of the effect of the peritectic transition on fragmentation and the CET in TiAl alloys. $\gamma$-TiAl alloys of technological interest have compositions around a peritectic plateau. 25 -mm diameter gravity-cast bars show marked structural differences between Ti-47Al-2Cr-2Nb and Ti-48Al-2Cr-2Nb, where a relatively small increase in aluminum content results in a narrower equiaxed zone and in finer and straighter columnar grains [30]. The peritectic transition appears to play a role in CET, but the mechanism is not yet understood.

In the present paper, the fragmentation and CET behavior of titanium aluminides with $\mathrm{Al}$ content around the peritectic, ranging from 43 to 52 at. $\%$, is investigated by characterizing as-cast alloy microstructures. A mechanism is proposed to explain the role of the peritectic reaction in fragmentation.

\section{Effect of aluminum content on the microstructure and grain size}

\subsection{Materials and Methods}

20-g ingots of gamma-TiAl were melted in a water-cooled $\mathrm{Cu}$ cold crucible semi-levitation induction furnace. Ti-47.5Al-2Cr-2Nb GE alloy furnished by Safran was used as a base, and additions of Ti (99.98\% purity, polished just before melting) or $\mathrm{Al}$ (99.99\% purity, polished just before melting), were made to achieve compositions as indicated in Table 1. The base composition is slightly hypoperitectic, and Ti-XAl-2Cr-2Nb compositions were selected around the peritectic.

The precursor GE alloy and alloying element were melted under Ar flow to prevent Al evaporation, after two vacuum-purge cycles followed by a vacuum in the range of $10^{-3}$ mbar. The cold crucible setup and the atmosphere used result in extremely low contamination of the samples. A bichromatic pyrometer mounted above the furnace tube recorded the thermal cycle. In cases where an alloying element was added, attaining a fully-liquid state coupled with a pyrometer reading above the liquidus temperature of the target composition indicated homogenization of the composition, after several melt-cooling cycles.

Once the samples were homogenized, they were remelted using the following protocol: After atmosphere preparation, Ar flow was started. Inductor parameters were: $7 \mathrm{~kW}$ power, $32 \mathrm{~A}$ current, $220 \mathrm{kHz}$ frequency, $5 \mathrm{mT}$ magnetic field. The resulting maximum liquid velocity, calculated from the energy balance between the electromagnetic field, the gravitational field, and the viscous dissipation [31] reaches $1.98 \cdot 10^{-1} \mathrm{~m} / \mathrm{s}$. The power level was gradually increased from 0 as the sample melted, stopping when the sample was fully liquid and the pyrometer showed a temperature above the expected liquidus temperature. After a few seconds at this temperature, the power to the generator was quickly ramped down manually. A superheat of around $18 \mathrm{~K}$ was reliably attained for all compositions using this method, and the thermal profile curves and sample microstructures shown to be reproducible. Three samples of each composition were produced to verify reproducibility. 
Completed samples were vertically cross-sectioned and manually polished to mirror finish (Struers OP-S colloidal silica solution, particle size $0.04 \mu \mathrm{m}$ ). Samples for SEM analysis were left as-is. Samples for macrostructure analysis were etched with a modified Kroll's reagent, $67 \%$ distilled water, $23 \% \mathrm{H}_{2} \mathrm{O}_{2}, 7 \% \mathrm{HF}$ and $3 \% \mathrm{HNO}_{3}$.

Grain size measurements were conducted by image analysis on a series of BSE SEM images of $\beta$-solidifying samples at low magnification in a FEI Quanta 600 FEG SEM. Increasing the contrast of the BSE images brought out the dark contour of the primary $\beta$ dendrites, which was traced manually. Image analysis was performed on the traced grain contours. Grain size measurements were carried out on a significant number of images and over 75 grains per sample in the equiaxed zone. The actual 3D grain size is calculated from 2D measurements using the equation $d_{g}^{(3 D)}=\frac{4}{\pi} d_{g}^{(2 D)}$ [32], and is hereafter denoted $d_{g}$.

[Table 1 about here.]

\subsection{Thermodynamics and thermal modeling}

Thermodynamic calculations have been performed using Thermo-Calc software. The database used is a quaternary Al-Cr-Nb-Ti description from V.T. Witusiewicz built from ternary Al-Nb-Ti [33] and Al-Cr-Ti [34] descriptions and assessed with complementary experiments based on Ti-Al-Cr-Nb alloys that enable a good agreement with experimental data. The commonly-available TiAl database by Saunders [35] is not totally able to reproduce the transformation temperatures and phase stability domains. The calculations were used to determine the solidification paths of the different alloys using the Scheil model (figure 1). The alloys ranging from 43 to $47.5 \% \mathrm{Al}$ begin solidification with the $\beta$ phase. The peritectic temperature evolves very little between the different alloys. Solidification continues with the $\alpha$ phase. The difference between the alloys is the amount of $\beta$ phase formed before the peritectic reaction and transformation starts. The alloy containing $52 \% \mathrm{Al}$ solidifies with the $\alpha$ phase as primary phase. From these calculations the liquidus temperatures, liquidus slopes $m_{i}^{\ell}$, partition coefficient $k_{i}(i=\mathrm{Al}, \mathrm{Cr}, \mathrm{Nb})$, and solidified fraction of pro-peritectic $\beta$ phase in the different alloys, which appear in Table 1, were determined.

\section{[Figure 1 about here.]}

Thermal gradients and solidification velocities were calculated using the finite-element-based COMSOL Multiphysics software. A 2D axisymmetric geometry was modeled by solving the heat transfer with phase change equations. Liquidus temperatures, solidification intervals and solidification enthalpies were taken from the thermodynamic calculations. Thermophysical properties were taken from ref. [36]. Boundary conditions for heat extraction from the copper mold were taken from ref. [37]. The convective heat exchange coefficient between the free surface and the argon flow has been chosen as $50 \mathrm{~W} / \mathrm{m}^{-2} \cdot \mathrm{K}^{-1}$. A good agreement was found with the pyrometric measurements and the predicted temperature evolution, and between the position of the shrinkage porosities observed on the different ingots and the area where the solidification ends in the simulations.

\subsection{Microstructure evolution}

Figures 2 (a-c) show the typical macrostructure and microstructure of as-cast ingots of the 43,46 and 47.5 at. $\%$ $\mathrm{Al}$ alloys. The alloy containing 45 at.\% $\mathrm{Al}$ is not shown because it is very similar to the alloy containing $43 \mathrm{Al}$. The macrostructure exhibits a columnar zone at the bottom lateral sides of the ingots where the liquid is first in contact with the cold crucible, followed by an equiaxed zone occupying the center part of the ingot. The dashed lines show the position of the CET and the vertical dashed lines indicate the position of the center of the ingot. The different grain contrast of the macrograph in Figure 2(c) is due to the secondary grain structure and is typical of hyper-peritectic Ti-Al alloys [25].

As can be seen from the BSE micrographs of the equiaxed zones, the microstructure evolves with the amount of aluminum since the solidification and transformation paths change accordingly. Despite the relatively low contrast of Figure 2 (a), corresponding to the ingot containing 43 at. $\% \mathrm{Al}$, the contour of the primary $\beta$ equiaxed grains can be seen on the micrographs. Inside these primary grains, a white array can be distinguished that corresponds to the enrichment of residual $\beta$ phase with $\beta$-stabilizing elements ( $\mathrm{Nb}$ and $\mathrm{Cr}$ ) and is typical of the $\beta \rightarrow \alpha$ phase transformation in titanium alloys and titanium aluminides. Around the equiaxed grains, the contrast is darkest due to aluminum segregation during solidification, and it increases with aluminum content. 
From the macro- and micrographs presented, the CET starts sooner in the ingots containing 46 and 47.5 at.\% Al compared to the one containing 43 at.\% Al. The BSE images have the same magnification and show an increasing number of primary $\beta$ grains for an increasing aluminum content in the ingot.

\section{[Figure 2 about here.]}

Figure 3 shows the measured equiaxed grain size of the different Al-containing ingots vs. the nominal aluminum content of the alloys. The specific points from the peritectic plateau, taken from an isopleth $\mathrm{Ti}-x \mathrm{Al}-2 \mathrm{Cr}-2 \mathrm{Nb}$ section are also indicated. While the alloys containing 43 and 45 at.\% Al show similar grain sizes of more than $500 \mu \mathrm{m}$, a sharp decrease of the grain size is observed for alloys containing 46 and 47.5 at.\% Al, as low as $293 \mu \mathrm{m}$, which is almost half that of the Ti-43Al-2Cr-2Nb alloy. The alloy containing 52 at.\% $\mathrm{Al}$ is fully columnar, and thus does not present any equiaxed grains.

[Figure 3 about here.]

From the grain size values, and assuming that a volume of $1 \mathrm{~m}^{3}$ is filled with grains of size $d_{g}$, the number of surviving fragments per $\mathrm{m}^{3}, N_{0}$, is estimated using the equation:

$$
d_{g}=\frac{1}{\sqrt[3]{N_{0}}}
$$

The resulting $N_{0}$ values are plotted against the equilibrium pro-peritectic fraction of $\beta$ phase in Figure 4, together with the results from Zollinger [25] obtained for binary Ti-Al and ternary Ti-Al-O alloys with $100 \mathrm{~K}$ superheat, produced with the same cold crucible furnace and analyzed with the same procedure (Section 2.1). In the Ti-x Al$2 \mathrm{Cr}-2 \mathrm{Nb}$ alloys, it can be seen that the number of fragments increases by one order of magnitude from $6 \cdot 10^{9}$ to $4 \cdot 10^{10}$ fragments $\cdot \mathrm{m}^{-3}$, while the amount of primary $\beta$ phase formed during solidification decreases from 0.83 to 0.42 . The $\mathrm{Ti}-\mathrm{Al}$ and $\mathrm{Ti}-\mathrm{Al}-\mathrm{O}$ alloys were cast with higher superheat (100 K vs. $20 \mathrm{~K}$ for $\mathrm{Ti}-x \mathrm{Al}-2 \mathrm{Cr}-2 \mathrm{Nb}$ alloys), so the increase in fragment density is less pronounced but still present. Moreover the increase in fragment density seems to occur at lower $\beta$ phase fractions, e.g. $f_{\beta}<0.3$ while in Ti-x $\mathrm{Al}-2 \mathrm{Cr}-2 \mathrm{Nb}$ alloys it is for $f_{\beta}<0.8$. The observed differences might have two origins. First, the Ti-Al and Ti-Al-O alloys were cast with a significantly higher superheat; dendrite fragments carried away in highly superheated liquid dissolve faster and can no longer contribute to the formation of the equiaxed structure. Solutal effects can also be important. Al, O and $\mathrm{Nb}$ have partition coefficients close to 1 , respectively $0.9,1.1$ and $1.2[38,39]$, but $\mathrm{Cr}$ segregates more into the liquid phase and can contribute to the solutal melting of the dendrite arm roots and thus favor fragmentation. At least in terms of the effect of superheat, these results are coherent with the observations from Tiwary and Beech on steels [18].

[Figure 4 about here.]

The fragmentation rate $\Phi$ (fragments. $\mathrm{m}^{-2} \mathrm{~s}^{-1}$ ), which is the number of fragments emitted at the columnar zone / liquid interface per second, was then estimated using:

$$
\Phi=\frac{N_{0} \cdot V_{\mathrm{e} q}}{A_{\mathrm{C} E T} \cdot \Delta t_{\mathrm{col}}^{\mathrm{g} r}}
$$

where $V_{\mathrm{e} q}$ is the volume of the equiaxed zone, $A_{\mathrm{C} E T}$ is the interfacial area between the columnar and equiaxed zone, and $\Delta t_{\mathrm{col}}^{\mathrm{g} r}$ is the time available for columnar growth. Finally the fragmentation rate per dendrite arm $\Phi_{\lambda_{1}}$ is calculated:

$$
\Phi_{\lambda_{1}}=\Phi \cdot \lambda_{1}^{2}
$$

where $\lambda_{1}$ is the primary arm spacing. The following model was used to calculate $\lambda_{1}$, relating the solidification velocity, the thermal gradient in the liquid and the mushy zone depth to the characteristic length as [40]:

$$
\lambda_{1}=4.3\left(\Gamma \sum_{i} \frac{-m_{i}^{\ell} x_{i}^{\circ}\left(1-k_{i}\right) D_{i}^{\ell}}{k_{i}}\right)^{\frac{1}{4}} v^{-\frac{1}{4}} G_{\ell}^{-\frac{1}{2}}
$$


$x_{i}^{\circ}$ is the nominal atomic fraction of solute $i . G_{\ell}$ and $v$ are calculated via finite-element modeling, partition coefficient and liquidus slope are determined using thermodynamic calculations and liquid diffusion coefficients are estimated at 5,2 and $1 \cdot 10^{-9} \mathrm{~m}^{2} \mathrm{~s}^{-1}$ for $\mathrm{Al}, \mathrm{Cr}$ and $\mathrm{Nb}$, respectively.

The results are summarized in Table 2 which shows that an order of magnitude separates the fragmentation rates of the alloy containing $43 \% \mathrm{Al}$ and the one containing $47.5 \% \mathrm{Al}$. The most telling result is the fragmentation rate per dendrite arm. For the $43 \% \mathrm{Al}$ alloy 10 dendrite arms reject 1 fragment into the melt per second, while for the $47.5 \%$ $\mathrm{Al}$ alloy, 1 single dendrite arm emits as many fragments per second.

[Table 2 about here.]

\subsection{Validation of the estimated surviving fragments}

The fragment densities and fragmentation rate presented in the previous section are difficult to compare with literature due to limited data available. However the values for the fragmentation rate $\Phi$ obtained in this work can be compared to the experiments of Moukassi on $\mathrm{Pb}-\mathrm{Sb}$ alloys in mechanically stirred melts where the liquid velocities reached 0.2 to $1 \mathrm{~m} . \mathrm{s}^{-1}$ [13]. Moukassi determined a fragmentation rate of $\approx 2.5 \cdot 10^{7}$ fragments.m $\mathrm{m}^{-2} \cdot \mathrm{s}^{-1}$, falling exactly within the range of fragmentation rate values determined here, from $1.95 \cdot 10^{7}$ to $1.41 \cdot 10^{8}$ fragments.m ${ }^{-2} \cdot \mathrm{s}^{-1}$.

Another possibility to check our experimental results is to use them as input for CET modeling. Hunt's criterion for CET involves the thermal gradient in the liquid, solidification velocity (and related constitutional undercooling $\Delta T_{c}$ ) and nucleation undercooling [28]. In this work, the nucleation undercooling is 0 , since the main source of equiaxed grains is considered to be dendrite fragmentation. Assuming that solutal undercooling is the main contributor to the dendrite tip undercooling, the criterion for a fully-equiaxed structure simplifies to:

$$
G_{\ell}>0.617 \sqrt[3]{N_{0}}\left(\Gamma \sum_{i}\left(\frac{-m_{i}^{\ell} x_{i}^{\circ}\left(1-k_{i}\right)}{D_{i}^{\ell}}\right) v\right)^{1 / 2}
$$

Using the experimental $N_{0}$ values determined from grain size analysis and the $G_{\ell}-v$ values calculated with the thermal finite element model, the solidification path can be superimposed on a Hunt $\log v(\log G)$ map. Results for the Ti-47.5Al-2Cr-2Nb alloy are shown in Figure 5. The total solidification time for the simulation was $14 \mathrm{~s}$, and only the first $5 \mathrm{~s}$ are indicated on the figure in order to visualize the CET position. Taking into account the relatively high temperature gradient and growth velocity $\left(\approx 20000 \mathrm{~K} \mathrm{~m}^{-1}\right.$ and $\left.\approx 10^{-3} \mathrm{~m} \mathrm{~s}^{-1}\right)$, the model reasonably predicts the CET position. The heat flow modeling reproduces the pyrometric data and position of the shrinkage porosity fairly well and can be considered accurate. Since the nucleation undercooling is taken to be equal to 0 here due to the absence of grain refiners, the only remaining variable in Hunt's model is the fragment density. The good agreement between Hunt's model and the experimental results suggest that the estimate of fragment densities is both quantitative and realistic.

\section{[Figure 5 about here.]}

\section{Grain refinement induced by the peritectic reaction in TiAl alloys}

A decrease in equiaxed grain size is observed experimentally when the amount of $\mathrm{Al}$ is increased, and the grain size corresponds with a realistic number of surviving fragments compared to Hunt's model. In order to obtain an equiaxed zone, a sufficient number of nuclei must exist in an undercooled liquid which allows them to grow ahead of the columnar grains.

In our experiments, although increasing the $\mathrm{Al}$ content decreases the liquidus temperature, care was taken to cast the ingots with a constant superheat of $18 \mathrm{~K}$. It is therefore reasonable to think that due to the forced convection imposed by the magnetic field, the temperature is quickly homogenized throughout the liquid and that due to the high heat transfer coefficient between the liquid alloy and the copper cold crucible, the overall (or macroscopic) thermal evolution during solidification is similar regardless of the alloy. The equiaxed grain size evolution appears to be related more to metallurgical effects than to thermal ones. 
Without grain refiners, it is admitted that fragmentation of columnar dendrites can be an origin of equiaxed nuclei. For efficiency's sake, this mechanism is decomposed into three steps: i) local remelting of a secondary dendrite arm, ii) detachment of a fragment iii) removal of the fragment outside the mushy zone to an undercooled area where it can grow as a new grain.

Local remelting can be attributed to recalescence induced by eutectic solidification [6], effects of solute pile-up, or advection of hot liquid favored by convection. In our configuration, no eutectic solidification occurs, and the rejected solute is enriched in $\mathrm{Al}$, leading to the absence of solute pile-up. Due to electromagnetic stirring, one can suppose that the penetration of the fluid flow into the mushy zone, which is closely related to its permeability [41], is the main reason for dendrite fragmentation. In order to compare this effect in TiAl-based alloys, the corresponding permeability has been calculated using the Carman-Kozeny relationship [42, 43], which becomes [41]:

$$
K=\frac{\lambda_{2}^{2}\left(1-f_{s}\right)^{3}}{180 \cdot f_{s}^{2}}
$$

where $\lambda_{2}$ is the secondary arm spacing. The evolution of the solid fraction with temperature was taken from the Thermo-Calc calculation presented in Figure 1. Due to the high thermal gradient and velocities together with the subsequent solid-state transformation that erases the solidification microstructure [44], it was not possible to measure the secondary arm spacing. The secondary arm spacing $\lambda_{2}$ was thus determined using the equation [45]:

$$
\lambda_{2}=5.5 \cdot\left(\frac{\Gamma \cdot t_{s}}{\frac{Q_{\mathrm{A} l}}{D_{\mathrm{A} l}^{\ell}}+\frac{Q_{\mathrm{C} r}}{D_{\mathrm{C} r}^{\ell}}+\frac{Q_{\mathrm{N} b}}{D_{\mathrm{N} b}^{\ell}}}\right)^{1 / 3}
$$

where $t_{s}$ is the local solidification time, and the growth restricting factor $Q_{i}$, represented here to condense thermodynamic factors into a single variable, is calculated for each element using the equation below [46] to yield the values in Table 3:

$$
Q_{i}=-m_{i}^{\ell} x_{i}^{\circ}\left(1-k_{i}\right)
$$

[Table 3 about here.]

Figure 6 presents the evolution of the permeability along the depth of the mushy zone for the two alloys and the corresponding changes in solid fraction. For the first millimeter of the mushy zone, there is no major difference between the two alloys due to the small difference in alloy composition in the same thermal gradient. The minimum distance into the mushy zone at which the partially remelted dendrites can become fragments is $8 \lambda_{2}$ [47] and the calculated values for the secondary dendrite arm spacing range from $8.94 \cdot 10^{-6} \mathrm{~m}$ for $43 \%$ Al to $7.20 \cdot 10^{-6} \mathrm{~m}$ for $47.5 \% \mathrm{Al}$. If the fragmentation mechanism driven by the fluid flow is the same for both alloys, there should not be such a difference in the determined fragmentation flux. Moreover, if based only on a remelting phenomenon due to fluid flow, Figure 6 shows that the permeability of the alloy containing $47.5 \% \mathrm{Al}$ decreases faster once the peritectic phase appears compared to the alloy containing $43 \% \mathrm{Al}$ which would lead to a decrease in the interdendritic flow and thus less fragmentation. This is in contradiction with the observations because in the case where the fragmentation mechanism depends only on permeability the observed grain size should be smaller in the alloy containing $43 \% \mathrm{Al}$.

[Figure 6 about here.]

The fragmentation mechanism occuring in the present experiments could be based on liquid film migration (LFM) as in the work of Boussinot et al. [48]. Their work shows the evolution of a peritectic microtructure involving a triple junction using phase field simulations. Boussinot et al. studied the temporal evolution of this triple junction at a temperature higher than the peritectic temperature. They showed that the microstructure evolves with a LFM process to a situation without a triple junction where the pro-peritectic and peritectic phase are divided and separated by a liquid film. This evolution is shown in Figure 7(a) where (i) and (ii) show the initial and final microstructure; the primary phase is $\beta$ and the peritectic phase is $\alpha$ in the Ti-Al system (whereas the primary and peritectic phases were labeled $\delta$ and $\gamma$ in Ref. [48]). Supporting this mechanism proposed from phase field simulation, recent experimental study on the migration of primary / peritectic interface [49] in directionally-solidified Sn-Ni alloys also clearly established that during isothermal annealing, liquid film migration can locally separate the primary and peritectic phases. 
In other words, re-heating a peritectic dendritic structure with hot liquid brought by the fluid flow (as in a classical fragmentation mechanism) could lead to the production of fragments induced by a LFM process at the peritectic triple point.

\section{[Figure 7 about here.]}

The dependence of the aluminum content on this mechanism is schematized in Figures 7(b) and (c). For the alloys containing 43 and $45 \% \mathrm{Al}$ (Figure 7(b)), the peritectic reaction occurs at solid fractions of 0.83 and 0.69 , respectively. At such a high solid fraction the blocking fraction $f_{\text {block }}$, defined as the critical solid fraction at which an equiaxed grain (or fragment) can no longer move, is probably reached. In a columnar zone, Bobadilla defined $f_{\text {block }}$ as the maximum of the ratio between the specific solid/liquid interface and the primary dendrite arm density [19] and found values ranging from 0.65 to 0.7 in stainless steels. The mechanism described above could therefor also be effective in the alloys containing 43 and $45 \% \mathrm{Al}$, without successful transport of the fragments out of the columnar zone. Moreover, at such a high solid fraction, the influence of the fluid flow is probably negligible due to the very low permeability, so only classical fragmentation can occur in these two alloys. Concerning the alloys containing 46 and 47.5\% Al (7(b)), the peritectic reaction occurs at lower solid fraction and thus higher permeability. The peritectic-induced fragments can then escape the mushy zone and contribute to the formation of equiaxed grains.

\section{Conclusions}

Ingots of $\gamma$-TiAl alloys based on Ti-47.5Al-2Cr-2 $\mathrm{Nb}$ were cast in a cold crucible induction furnace and characterized. Equiaxed primary grain size was found to decrease as aluminum content increases and pro-peritectic $\beta$ content decreases. Accurate estimates of dendrite fragmentation and the fragmentation rate were made and used to predict the CET position. Dendrite fragmentation was thought to be the primary cause of fragmentation in these nongrain-refined ingots, and peritectic solidification appears to contribute to fragmentation. For the compositions studied, fragmentation occurs for a lower solid fraction in hypoperitectic compositions closer to the peritectic point, which facilitates the escape of the fragment through the more open dendritic structure closer to the tip, where fluid flow can more effectively transport them to the undercooled liquid.

\section{Ackowledgements}

This work was carried out as part of the GRADECET (GRAvity DEpendence of Columnar to Equiaxed Transition in TiAl Alloys) research project.

\section{References}

[1] R. Rosenhain, J. Inst. Metals 35 (1926) 282-285.

[2] B. Chalmers, J. Aust. Inst. Met. 8 (1963] 255-263.

[3] T.P. Melia and W.P. Moffitt, Ind. Eng. Chem. Fundamen. 3 (1964) 313-317.

[4] K.A. Jackson, J.D. Hunt, D.R. Uhlmann and T.P. Seward, Trans. Metall. AIME 236 (1966) 149-158.

[5] T. Sato, W. Kurz and K. Ikawa, Trans. Jpn. I. Met. 28 (1987) 1012-1021.

[6] R.H. Mathiesen, L. Arnberg, P. Bleuet and A. Somogyi, Metall. Mater. Trans. 37A (2006) 2515-2524.

[7] D. Ruvalcaba, R.H. Mathiesen, D.G. Eskin, L. Arnberg, L. Katgerman, Acta Mater. 55 (2007) 4287-4292.

[8] E. Liotti, A. Lui, R. Vincent, S. Kumar, Z. Guo, T. Connolley, I.P. Dolbnya, M. Hart, L. Arnberg, R.H. Mathiesen, P.S. Grant, Acta Mater. 70 (2014) 228-239.

[9] C. Bi, Z. Guo, E. Liotti, S. Xiong, P.S. Grant, Acta Metall. Sin. 51 (2015) 685-692.

[10] N. Shevchenko, O.Roshchupkina, O.Sokolova, S.Eckert, J. Cryst. Growth 417 (2015) 1-8.

[11] T. Nagira, N. Nakatsuka, H. Yasuda, K. Uesugi, A. Takeuchi, Y. Suzuki, Mater. Lett. 150 (2015) $135-138$.

[12] G. Hansen, A. Hellawell, S.Z. Lu and R.S. Steube, Metall. Mater. Trans. 27A (1996) 569-581.

[13] M. Moukassi, PhD thesis, INPL, Nancy, France, 1988.

[14] C.J. Paradies, R.N. Smith and M.E. Glicksman, Metall. Mater. Trans. 28A (1997) 875-879.

[15] G. Lesoult, P. Neu and J.P. Birat, Proceedings of the Symposium of the International Union of Theoretical and Applied Mechanics, TrinityCollege, Cambridge, UK, September 1982, 169-179.

[16] A. Hellawell, S. Liu and S.Z. Lu, JOM J. Min. Met. Mat. S. (1997) 18-20.

[17] P.A. Bibby and J. Beech, JISI 211 (1973) 290-292.

[18] S.N. Tiwary, J. Beech, Trans. ISIJ 21 (1981) 554-558. 
[19] M. Bobadilla, PhD Thesis, Ecole des Mines de Paris, 1984

[20] H.W. Kerr, J. Cisse, G.F. Bolling, Acta Metall. 22 (1974) 677-686.

[21] J. Valloton, J.A. Dantzig, M. Plapp, M. Rappaz, Acta Mater. 61 (2013) 5549-5560.

[22] T.S. Lo, S. Dobler, M. Plapp, A. Karma, Acta Mater. 51 (2003) 599-611.

[23] J. Valloton, J.-D. Wagnire, M. Rappaz, Acta Mater. 60 (2012) 3840-3848

[24] H. Yasuda, T. Nagira, M. Yoshiya, N. Nakatsuka, M. Kiire, A. Sugiyama, K. Uesugi, K. Umetani, IOP Conf. Series: Mater. Sci. Eng. 27 (2011) 012084.

[25] J. Zollinger, PhD Thesis, INPL, Nancy, France, 2008.

[26] J. Eiken, M. Apel, V.T. Witusiewicz, J. Zollinger and U. Hecht, J. Phys.: Condens. Mat. 21 (2009) 464104.

[27] J.A. Spittle, Int. Mater. Rev 51 (2006) 247-269.

[28] J.D. Hunt, Mater. Sci. Eng. 65 (1984) 75-83.

[29] H. Biloni and B. Chalmers. J. Mat. Sci. 3 (1968) 139-149.

[30] M. Thomas, J.L. Raviart, F. Popoff, Intermetallics 14 (2005) 944-951.

[31] D.M. Herlach, Crystals 5 (2015) 355-375.

[32] M. Kong, R.N. Bhattacharya, C. James, and A. Basu, Geol. Soc. Am. Bull. 117 (2005) 244-249.

[33] V.T. Witusiewicz, A.A. Bondar, U. Hecht, T.Ya. Velikanova, J. Alloy. Comp. 472 (2009) 133-161.

[34] V.T. Witusiewicz, A.A. Bondar, U. Hecht, T.Ya. Velikanova, J. Alloy. Comp. 644 (2015) 939-958.

[35] N. Saunders, "TiAl DATA, a thermodynamic database for calculation of phase equilibria in multicomponent TiAl alloys. Surrey Technology Centre, Guilford: Thermotech Ltd.; 1997.

[36] C. Cagran, B. Wilthan, G. Pottlacher, B. Roebuck, M. Wickins, R.A. Harding, Intermetallics 11 (2003) 1327-1334.

[37] D.R. Liu, J.J. Guo, S.P. Wu, Y.Q. Su, H.Z. Fu, Mater. Sci. Eng. A 415 (2006) 184-194.

[38] J. Zollinger, J. Lapin, D. Daloz, H. Combeau, Intermetallics, 15 (2007) 1343-1350.

[39] D. Daloz, U. Hecht, J. Zollinger, H. Combeau, A. Hazotte, M. Založnik, Intermetallics 19 (2011) 749-756.

[40] W. Kurz and D.J. Fisher, Fundamentals of Solidification. 4th revised ed. 1998, Uetikon-Zuerich: Trans Tech Publications.

[41] T. Campanella, C. Charbon, M. Rappaz, Scripta Mater 49 (2003) 1029-1034.

[42] M. Rappaz, M. Bellet, M. Deville, Numerical modeling in materials science and engineering. Berlin, Heidelberg: Springer-Verlag (2003).

[43] P. C. Carman, Trans Inst Chem 15 (1937) 150-166.

[44] J. Zollinger, Z. Gabalcová, D. Daloz, J. Lapin, H. Combeau, Kovove Mater. 46 (2008) 291-296.

[45] J. Dantzig, M. Rappaz, Solidification, EPFL Press (2009).

[46] M. Easton, D. StJohn, Metall. Mater. Trans. A 36 (2005) 19111920

[47] T. Campanella, C. Charbon, M. Rappaz, Metall. Mater. Trans. A 35 (2004) 32013210

[48] G. Boussinot, E.A. Brener, D.E. Temkin, Acta Mater. 58 (2010) 1750-1760.

[49] P. Peng, X. Li, J. Li, Y. Su, J. Guo, H. Fu, Sci Rep 6 (2016) 24512. 


\section{List of Figures}

1 Scheil solidification path calculated for the alloys studied. The peritectic Liquid $+\beta \rightarrow \alpha$ temperature is indicated with a black dot and Liquid $+\alpha \rightarrow \gamma$ temperature is indicated with a black square. . .

2 OM macrostructures showing half of the ingot and SEM/BSE details of the equiaxed microstructures of the alloys containing (a) $43 \% \mathrm{Al}$, (b) $46 \% \mathrm{Al}$ and (c) $47.5 \% \mathrm{Al}$. The white dashed lines indicate the CET position and the vertical dashed line indicates the center of the ingots where the CET measurements were made for comparison with Hunt's model. . . . . . . . . . . . . . . . . . . .

3 Average equiaxed grain size vs. aluminum content. Points from the peritectic plateau determined via thermodynamic calculations are also indicated. No equiaxed grains were observed in Ti-52Al-2Cr$2 \mathrm{Nb}$ alloy. . . . . . . . . . . . . . . . . . . . . . . . . . 12

4 Estimated surviving fragments plotted against the equilibrium amount of pro-peritectic phase for the present work and with the data analyzed from Ref. [25]. . . . . . . . . . . . . . . . . . . . 13

5 Comparison of the Hunt criterion for CET including experimental $N_{0}$ with thermal gradients and velocities calculated with the finite-element modeling for the GE Ti-47.5Al-2Cr-2Nb alloy. Experimental position of the CET is also indicated. . . . . . . . . . . . . . . . . . . . 14

6 Permeability and solid fraction as a function of distance from dendrite tip for $43 \% \mathrm{Al}$ and $47.5 \% \mathrm{Al}$. (a) Evolution with time of a triple junction above the peritectic temperature at (i) $t=0$ and (ii) $t=1$ (normalized time). Redrawn from Ref. [48] with the Ti-Al system phases. (b) and (c) shows schematically the cases where the peritectic reaction induces fragmentation : (b) at high solid fraction, the fragment is surrounded by dendrite arms and remains in the mush and (c) at low solid fraction, the produced fragment is still unconfined and can escape the mush. . . . . . . . . . . . . . . 


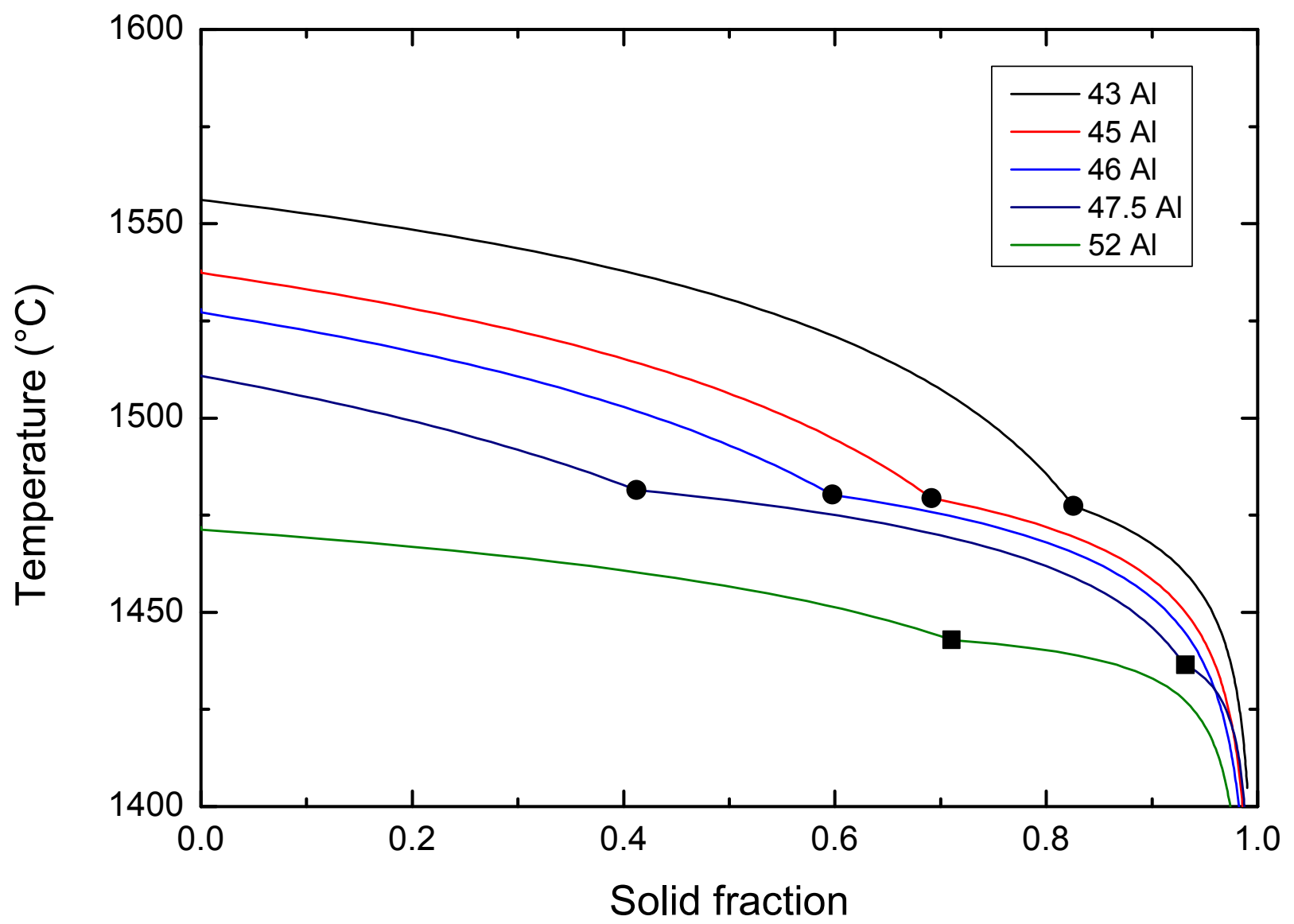

Figure 1: Scheil solidification path calculated for the alloys studied. The peritectic Liquid $+\beta \rightarrow \alpha$ temperature is indicated with a black dot and Liquid $+\alpha \rightarrow \gamma$ temperature is indicated with a black square. 

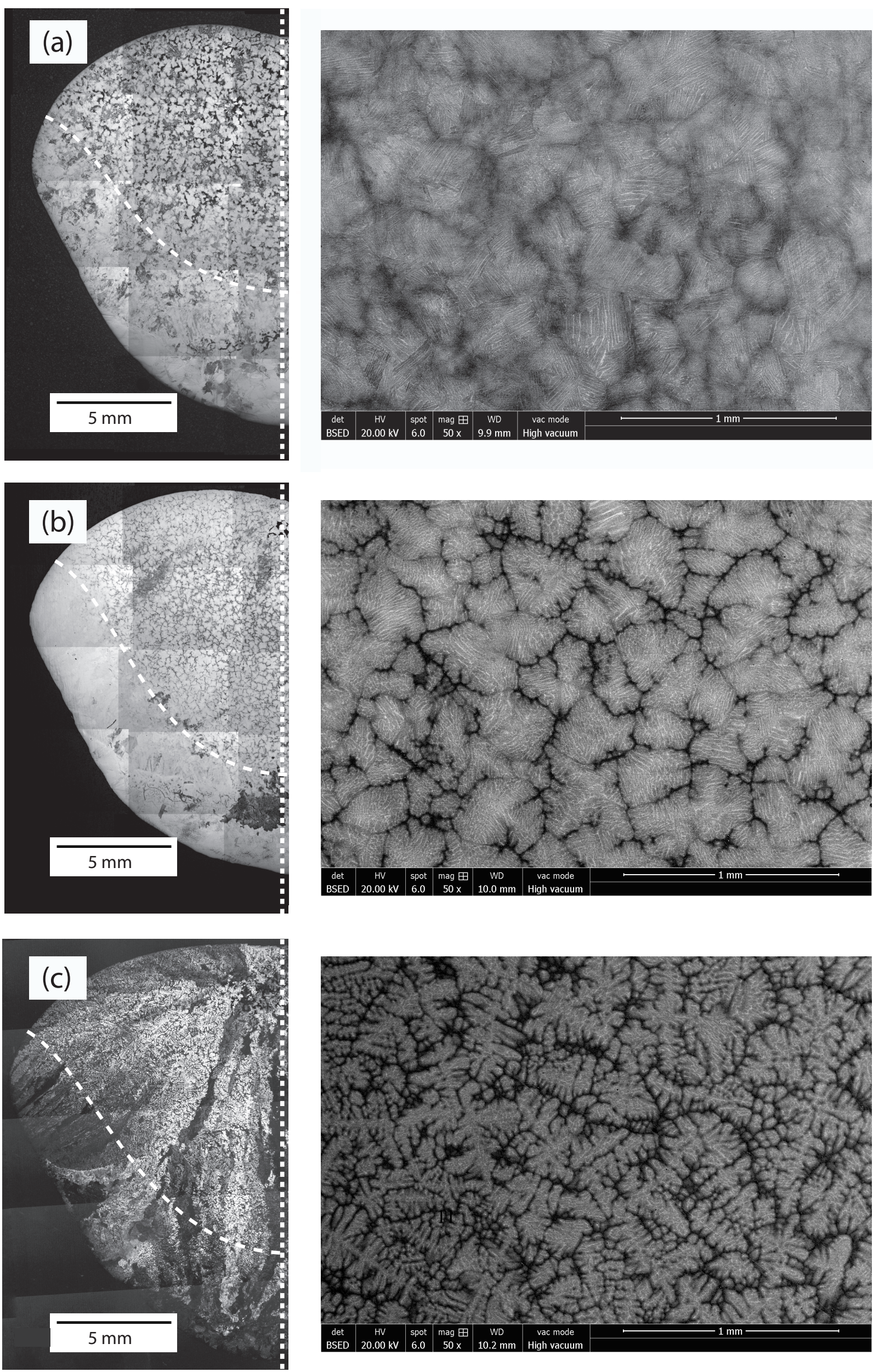


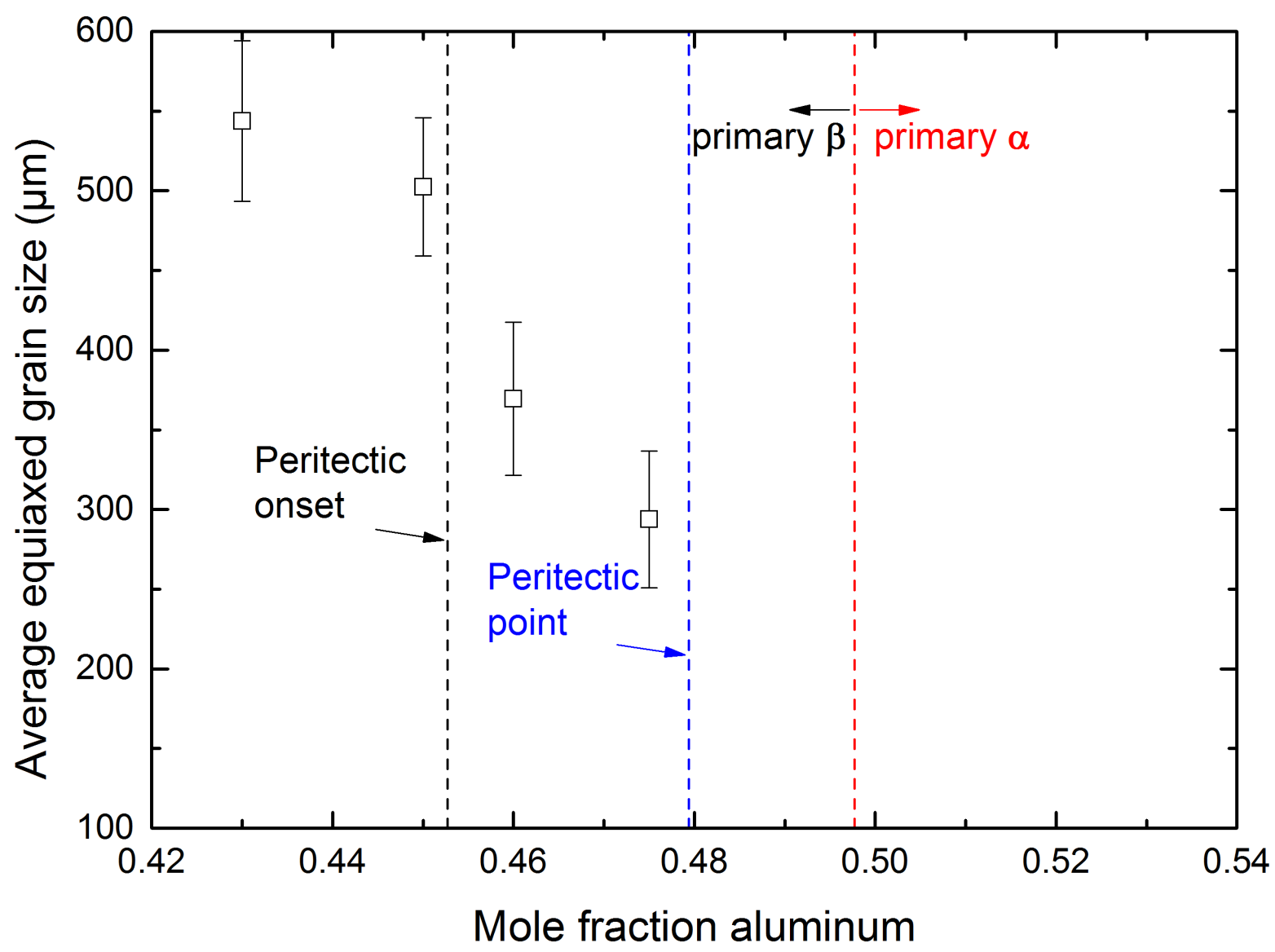

Figure 3: Average equiaxed grain size vs. aluminum content. Points from the peritectic plateau determined via thermodynamic calculations are also indicated. No equiaxed grains were observed in Ti-52Al-2Cr-2Nb alloy. 


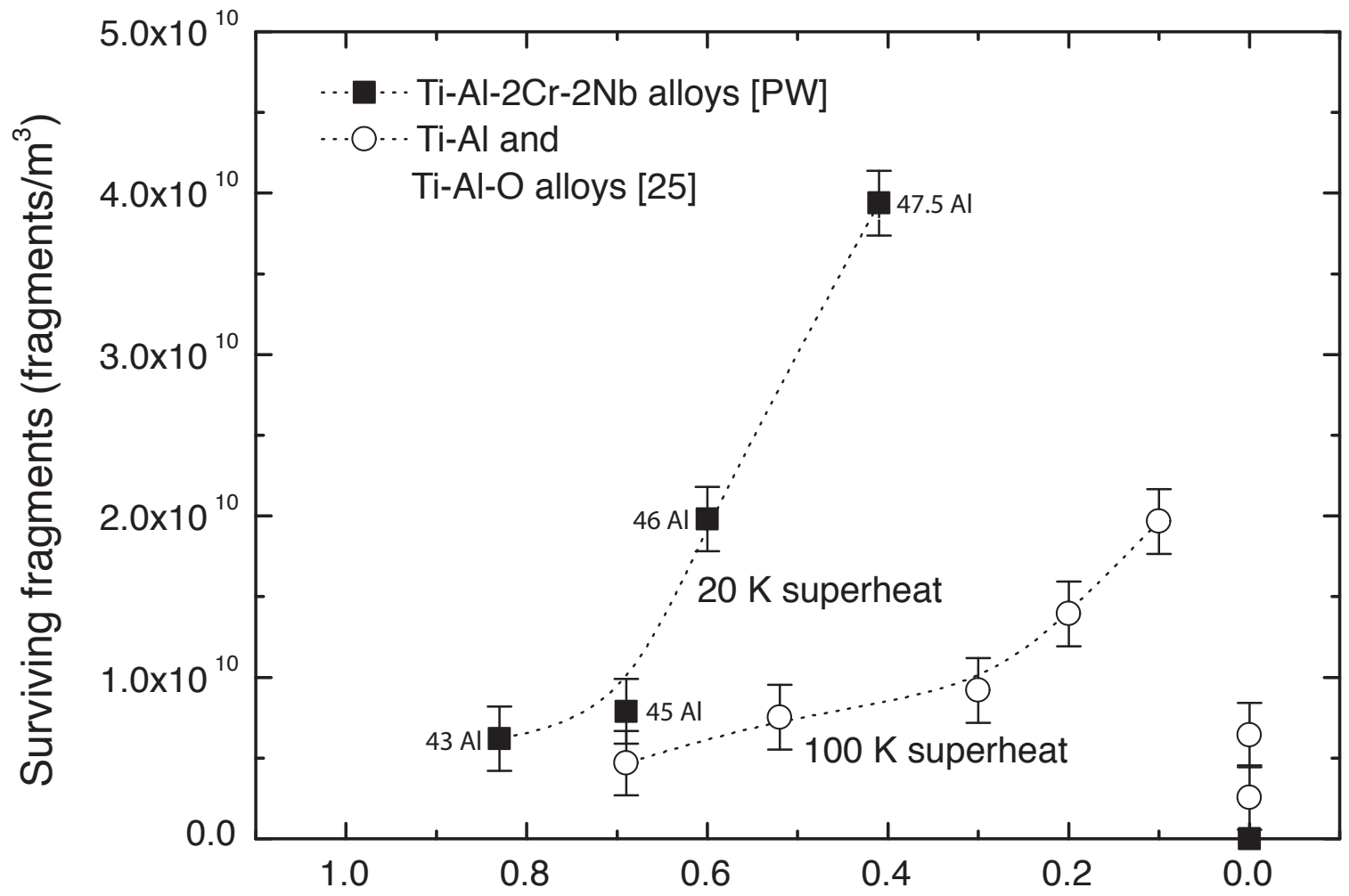

Equilibrium pro-peritectic phase atomic fraction

Figure 4: Estimated surviving fragments plotted against the equilibrium amount of pro-peritectic phase for the present work and with the data analyzed from Ref. [25]. 


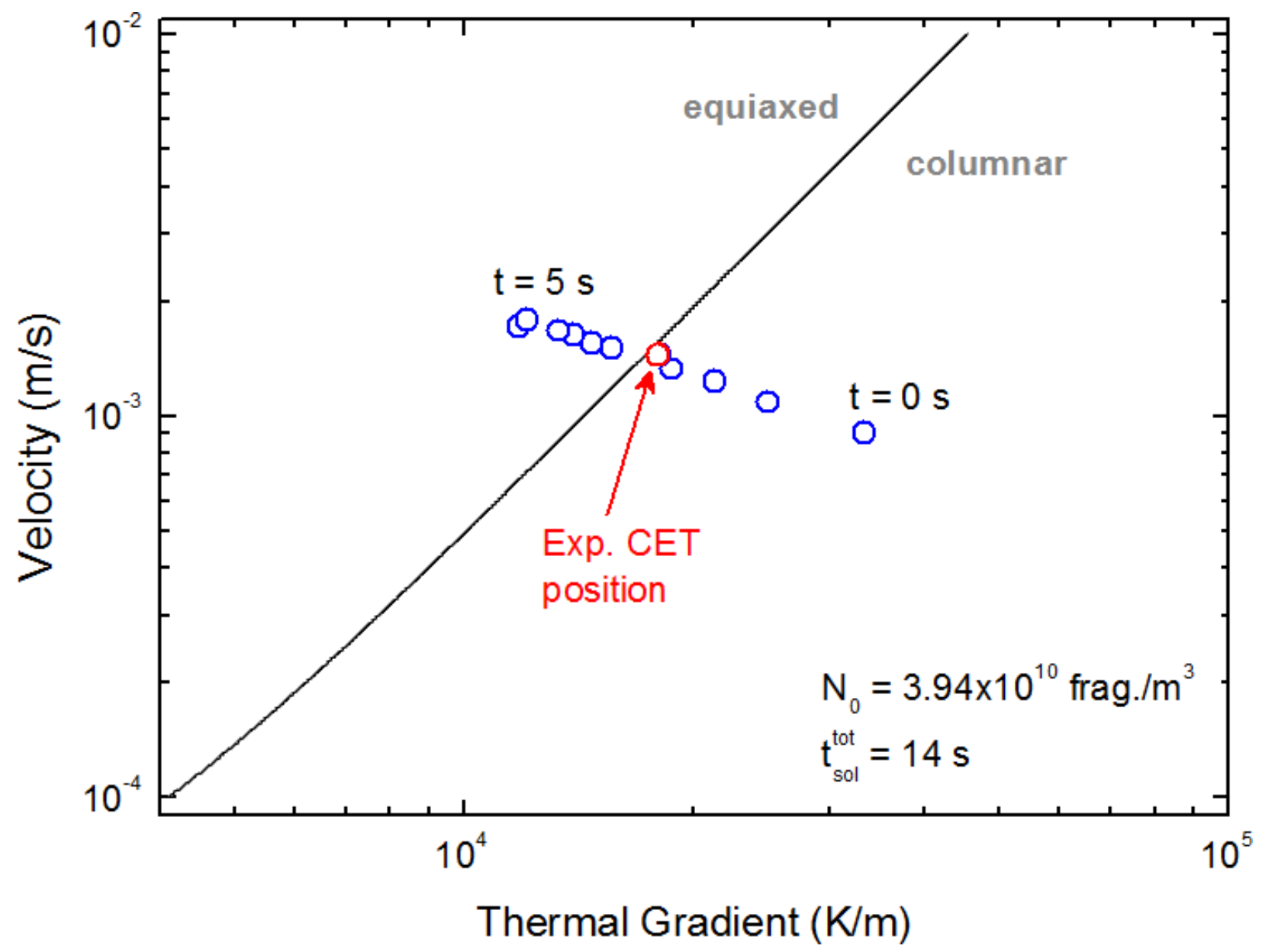

Figure 5: Comparison of the Hunt criterion for CET including experimental $N_{0}$ with thermal gradients and velocities calculated with the finiteelement modeling for the GE Ti-47.5Al-2Cr-2Nb alloy. Experimental position of the CET is also indicated. 


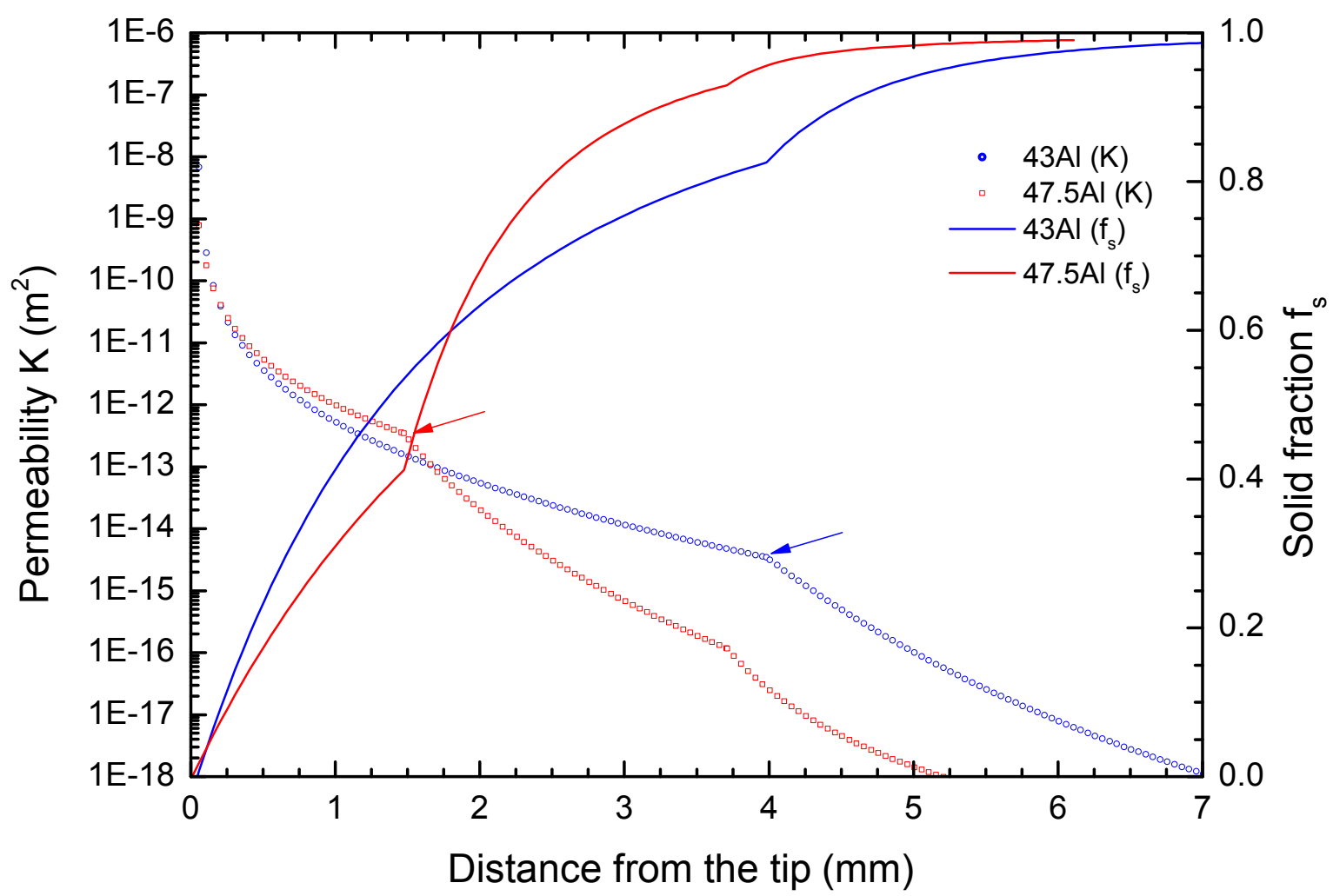

Figure 6: Permeability and solid fraction as a function of distance from dendrite tip for $43 \% \mathrm{Al}$ and $47.5 \% \mathrm{Al}$. 


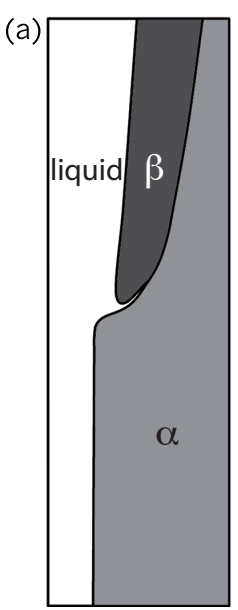

(i)

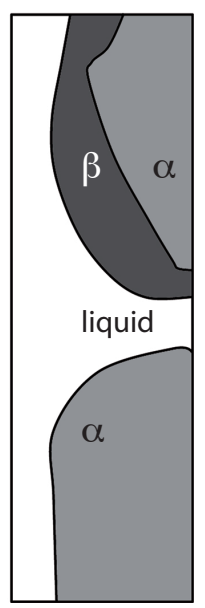

(ii) (b)

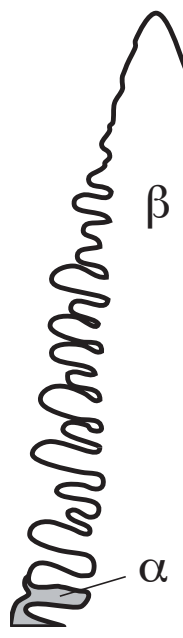

$\mathrm{Ti}-43 \mathrm{Al}-2 \mathrm{Cr}-2 \mathrm{Nb}-\mathrm{f}_{\beta}=0.83$

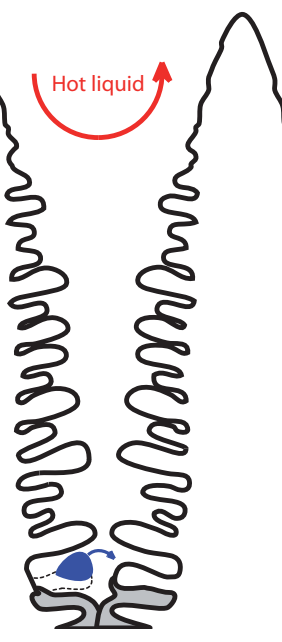

(c)

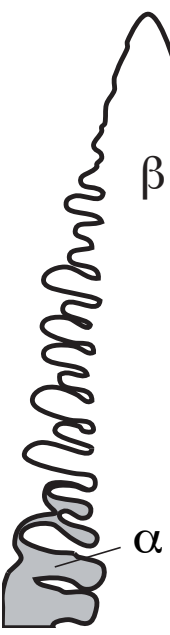

(c)
$\mathrm{Ti}-47.5 \mathrm{Al}-2 \mathrm{Cr}-2 \mathrm{Nb}-\mathrm{f}_{\beta}=0.42$
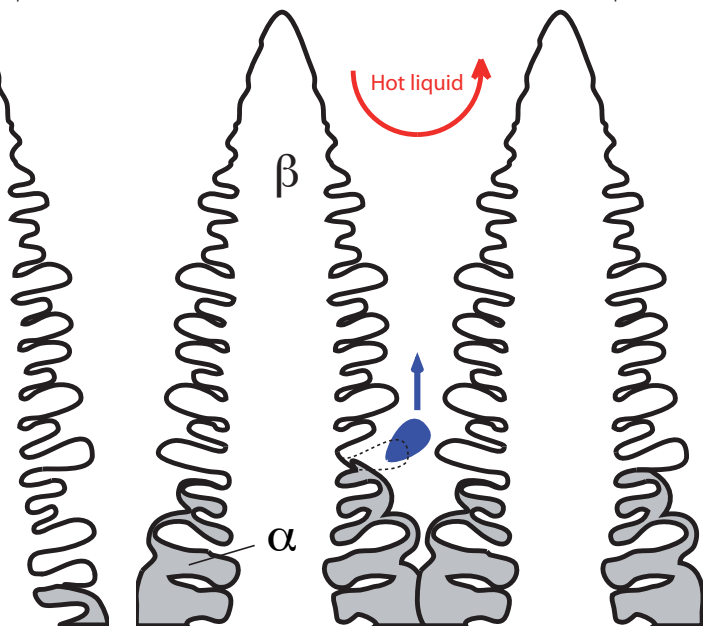

Figure 7: (a) Evolution with time of a triple junction above the peritectic temperature at (i) $t=0$ and (ii) $t=1$ (normalized time). Redrawn from Ref. [48] with the Ti-Al system phases. (b) and (c) shows schematically the cases where the peritectic reaction induces fragmentation : (b) at high solid fraction, the fragment is surrounded by dendrite arms and remains in the mush and (c) at low solid fraction, the produced fragment is still unconfined and can escape the mush. 


\section{List of Tables}

1 Nominal and measured aluminum composition together with the data determined from thermodynamic calculations: liquid temperature, liquidus slopes, partition coefficients and fraction of primary $\beta$ phase. . . . . . . . . . . . . . . . . . . . . . . 18

2 Average measured superheat, equiaxed grain size, surviving fragments, fragmentation rate and fragmentation rate per primary dendrite arm for the 5 compositions studied. . . . . . . . . . . . . . 19

3 Growth restricting factor $\left(Q_{i}\right)$ values for the alloys studied. . . . . . . . . . . . . . . . . 20 


\begin{tabular}{|c|c|c|c|c|c|c|c|c|c|}
\hline \multirow{2}{*}{$\begin{array}{c}\text { Nominal Al } \\
\text { content (at.\%) }\end{array}$} & \multirow{2}{*}{$\begin{array}{l}\text { Measured } \mathrm{Al} \text { content } \\
\text { equiaxed zone, (at.\%) }\end{array}$} & \multirow{2}{*}{$\mathrm{T}_{\ell}(\mathrm{K})$} & \multicolumn{3}{|c|}{$m_{i}^{\ell}$ (K/at.\%) } & \multicolumn{3}{|c|}{$k_{i}$} & \multirow{2}{*}{$f_{\mathrm{p} r o}^{\beta}$} \\
\hline & & & $\mathrm{Al}$ & $\mathrm{Cr}$ & $\mathrm{Nb}$ & $\mathrm{Al}$ & $\mathrm{Cr}$ & $\mathrm{Nb}$ & \\
\hline 43 & 44.18 & 1829 & -997 & -12951 & 8377 & 0.92 & 0.87 & 1.20 & 0.83 \\
\hline 45 & 46.26 & 1811 & -1088 & -17359 & 9679 & 0.92 & 0.88 & 1.21 & 0.69 \\
\hline 46 & 46.99 & 1800 & -1142 & -19974 & 10326 & 0.92 & 0.89 & 1.21 & 0.60 \\
\hline 47.5 & 48.71 & 1784 & -1232 & -24572 & 11420 & 0.91 & 0.90 & 1.22 & 0.41 \\
\hline 52 & 52.57 & 1744 & -872 & -3370 & 3879 & 0.96 & 0.71 & 1.26 & 0 \\
\hline
\end{tabular}

Table 1: Nominal and measured aluminum composition together with the data determined from thermodynamic calculations: liquid temperature, liquidus slopes, partition coefficients and fraction of primary $\beta$ phase. 


\begin{tabular}{cccccc}
\hline $\begin{array}{c}\text { Al content } \\
(\text { at.\% })\end{array}$ & $\begin{array}{c}\Delta T_{s h} \\
(K)\end{array}$ & $\begin{array}{c}\text { G. S. } \\
(\mu \mathrm{m})\end{array}$ & $\begin{array}{c}\text { S. F. } \\
\left(\mathrm{m}^{-3}\right)\end{array}$ & $\begin{array}{c}\Phi \\
\left(\mathrm{m}^{-2} . \mathrm{s}^{-1}\right)\end{array}$ & $\begin{array}{c}\Phi_{\lambda_{1}} \\
\left(\mathrm{arm}^{-1} . \mathrm{s}^{-1}\right)\end{array}$ \\
\hline 43 & 17 & 544 & $6.20 \cdot 10^{9}$ & $1.95 \cdot 10^{7}$ & 0.10 \\
45 & 23 & 502 & $7.90 \cdot 10^{9}$ & $2.23 \cdot 10^{7}$ & 0.12 \\
46 & 18 & 369 & $1.98 \cdot 10^{10}$ & $5.10 \cdot 10^{7}$ & 0.29 \\
47.5 & 17 & 293 & $3.94 \cdot 10^{10}$ & $1.41 \cdot 10^{8}$ & 0.85 \\
52 & 18 & $/$ & 0 & 0 & 0 \\
\hline
\end{tabular}

Table 2: Average measured superheat, equiaxed grain size, surviving fragments, fragmentation rate and fragmentation rate per primary dendrite arm for the 5 compositions studied. 


\begin{tabular}{cccc}
\hline Nominal Al content (at.\%) & $\mathrm{Q}_{A l}$ & $\mathrm{Q}_{C r}$ & $\mathrm{Q}_{N b}$ \\
\hline 43 & 33.40 & 33.45 & 33.47 \\
45 & 40.01 & 40.11 & 40.14 \\
46 & 43.77 & 43.84 & 43.85 \\
47.5 & 50.19 & 50.36 & 50.41 \\
52 & 19.83 & 19.77 & 19.93 \\
\hline
\end{tabular}

Table 3: Growth restricting factor $\left(Q_{i}\right)$ values for the alloys studied. 